\title{
ESTRESSE OXIDATIVO NOS ESTÁGIOS FINAIS DA DOENÇA RENAL CRÔNICA EM PEQUENOS ANIMAIS
}

\section{Oxidative stress in end-stage chronic kidney disease in small animals}

\begin{abstract}
GALVÃO, A.L.B. ${ }^{1}$
1 Pós-graduando em Medicina Veterinária da Faculdade de Ciências Agrárias e Veterinárias

(FCAV/UNESP), Jaboticabal, SP.

Endereço para correspondência: André Luiz Baptista Galvão: andrelgalvao@hotmail.com

\section{RESUMO}

A doença renal crônica (DRC) é caracterizada por lesões estruturais irreversíveis, que podem evoluir progressivamente para uremia e insuficiência renal crônica (IRC). Na IRC ocorre a incapacidade de executar adequadamente as funções de manutenção do equilíbrio hidroeletrolítico e ácido-base, excreção de catabólitos e regulação hormonal. Quando se analisa o mecanismo fisiopatológico dos transtornos renais, observa-se que fatores presentes, predispõem ao desequilíbrio oxidativo. Na maioria das vezes, o paciente renal apresenta-se mal nutrido, com carência em reservas de vitaminas e minerais, o que diminui os mecanismos de defesa antioxidantes e favorece a instalação do estresse oxidativo renal, com a formação de espécies reativas do metabolismo do oxigênio (ERMO), substâncias estas potencialmente lesivas ao organismo. A redução da taxa de filtração glomerular (TFG) na evolução da DRC em cães e gatos é um componente para a instalação do estresse oxidativo renal. As ERMO possuem ação importante nos rins são altamente reativas e quando presentes em excesso danificam lipídios, proteínas, DNA e carboidratos, conduzindo anormalidades funcionais e estruturais que induzem a apoptose celular e necrose. Contra a ação potencialmente lesiva destas substâncias reativas, torna-se fundamental um delicado controle de sua produção e consumo no meio intracelular, ou seja, um equilíbrio de sua concentração intra e extracelular. Isto é possível devido à atividade dos antioxidantes. Assim, a presente revisão de literatura teve como objetivo descrever a participação do estresse oxidativo na IRC, como também os mecanismos de defesa frente à ação lesiva dessas substâncias.
\end{abstract}

Palavras-chave: antioxidantes; cães; doença renal; gatos

\section{ABSTRACT}

The chronic kidney disease (CKD) it is characterized by irreversible structural lesions that can develop progressively for uremia and chronic renal failure (CRF). In the CRF it happens the incapacity of executing the functions of maintenance of the electrolyte balance and acid-base, catabolitos excretion and hormonal regulation appropriately. When the mechanism basic physiopathology of the renal upset is analyzed, it is observed that present factors, predispose to the unbalance oxidative. Most of the time, the renal patient comes badly nurtured, with lack in reservations of vitamins and minerals, what reduces the antioxidant defense mechanisms, what favors the installation of the renal oxidative stress, with the formation of species you reactivate of reactive oxygen species (ROS), substances these potentially harmful to the organism. The reduction of the glomerular filtration rate (GFR) in the evolution of CKD in dogs and cats is a component for the installation of the renal oxidative stress. The ROS possesses important action in the kidneys, and these substances are highly reactivate, and when presents in excess damage lipids, proteins, DNA and carbohydrate, driving functional and structural abnormalities taking the cellular apoptosis and necrosis. Against the harmful potential action of these substances you reactivate, she becomes fundamental a delicate control of his production and consumption in the half intracellular, in other words, a balance of his concentration intra and extracellular. That is possible due to the activity of the antioxidants. Like this, to present literature revision had as objective describes the participation of the oxidative stress in CRF, as well as the mechanisms defenses against the harmful action of those substances.

Key words: antioxidants; cats; dogs; kidney disease 


\section{INTRODUÇÃO}

A doença renal crônica (DRC) é caracterizada por lesões estruturais irreversíveis, que podem evoluir progressivamente para uremia e insuficiência renal crônica (IRC). A IRC é caracterizada nos estágios II e III na evolução da doença renal em cães e gatos (Polzin et al., 2005; IRIS, 2006). Na insuficiência renal crônica (IRC) ocorre a incapacidade de executar adequadamente as funções de manutenção do equilíbrio hidroeletrolítico e ácidobase, excreção de catabólitos e regulação hormonal (Mafra et al., 1999; Luciak, 2004). Independentemente da causa inicial, os animais acometidos pela IRC, apresentam lesões estruturais, irreversíveis no parênquima renal (Polzin et al., 2005). Estima-se que somente após a perda irreversível de mais de $75 \%$ da capacidade funcional, inicia-se a manifestação dos sinais de uremia, cuja intensidade varia em cada paciente (Brown et al., 1997).

O gradual aumento da disfunção renal compromete também a capacidade funcional de outros órgãos, resultando no aparecimento da síndrome urêmica (Polzin et al., 2000). No decorrer da evolução da IRC, e na dependência do grau de comprometimento renal, observa-se o comprometimento de outros sistemas orgânicos tais como digestório (Senior, 1994; Polzin et al., 2000), cardiovascular (Ross, 1992), esquelético (Nagode, 1990; Feldman, 1995), nervoso (Mahoney e Arieff, 1983, Polzin e Osborne, 1986) e hematopoético (King et al, 1992; Senior, 2001). As manifestações clínicas ocorrem isoladamente ou em conjunto (Polzin et al., 2000). Os sintomas inicialmente observados pelos proprietários de cães estão relacionados à diminuição da capacidade de concentrar urina (Nichols, 2001), refletindo a perda de parte considerável da capacidade funcional dos rins (Polzin e Osborne, 1986).
Quando se analisa o mecanismo fisiopatológico básico dos transtornos renais, observa-se que fatores presentes, predispõem ao desequilíbrio oxidativo. $\mathrm{Na}$ maioria das vezes, o paciente renal apresenta-se mal nutrido, com carência em reservas de vitaminas e minerais, o que diminui os mecanismos de defesa antioxidantes, o que favorece a instalação do estresse oxidativo renal, com a formação de espécies reativas do metabolismo do oxigênio (ERMO), substâncias estas potencialmente lesivas ao organismo (Galle, 2001; Scott, 2008).

Contra a ação potencial lesiva destas substâncias reativas, torna-se fundamental um delicado controle de sua produção e consumo no meio intracelular, ou seja, um equilíbrio de sua concentração intra e extracelular. Isto é possível devido à atividade dos antioxidantes, que removendo as substâncias reativas, as mantêm em baixas concentrações (Laurindo, 2003; Bernabeu et al., 2004).

Os antioxidantes podem ser intracelulares (glutationa, superóxido dismutase, catalase, peroxidases), ou agirem em membrana celular como o betacaroteno, flavonóides e as vitaminas $\mathrm{C}$ e $\mathrm{E}$ (Laurindo, 2003).

Desse modo a presente revisão de literatura teve como objetivo descrever a participação do estresse oxidativo na IRC, como também os mecanismos de defesas contra a ação lesiva dessas substâncias deletérias ao organismo.

\section{DESENVOLVIMENTO} crônica

Estresse oxidativo na doença renal

Quando se estuda o mecanismo fisiopatológico básico dos transtornos renais, observa-se que fatores presentes predispõem ao desequilíbrio oxidativo. Geralmente, o paciente renal apresenta-se mal nutrido, com carência em reservas de 
vitaminas e de minerais, o que diminui os mecanismos antioxidantes de defesa (Galle, 2001; Scott, 2008). Não raramente, os doentes também podem apresentar fenômenos isquêmicos e tóxicos que podem provocar danos tubulares de maneira aguda, assim como danos glomerulares de origem imunológica. Essas lesões podem vir acompanhadas da geração excessiva de compostos oxidantes, o que, juntamente com a insuficiência dos mecanismos de defesa antioxidante, levam ao estresse oxidativo (Brown et al., 1997; Bernabeu et al., 2004; Scott, 2008).

Vários autores acreditam que 0 estresse oxidativo é um fator potencialmente importante na mortalidade dos pacientes com IRC e mediador de muitas complicações, principalmente cardiovasculares e neurológicas, pois está envolvido na patogênese da hipertensão arterial sistêmica, disfunção endotelial e inflamação (Zafarullah et al., 2003; Bernabeu et al., 2004; Shimizu, 2005; Scott, 2008).

Outros pesquisadores também verificaram, em pacientes com IRC, uma peroxidação lipídica mais intensa em eritrócitos e outras células sanguíneas em pacientes humanos renais crônicos, os quais apresentaram valores reduzidos de antioxidantes enzimáticos. As lesões oxidativas alteram a fluidez da membrana dos eritrócitos, o que contribui para hemólise e piora da anemia, além do aumento da oxidação das lipoproteínas de baixa densidade derivadas do colesterol, que exercem um papel importante na patogênese da aterosclerose (McGrath et al., 1995; Panzetta et al., 1995)

A redução da taxa de filtração glomerular (TFG) na evolução da IRC em cães e gatos é um componente para a instalação do estresse oxidativo renal. Uma variedade de moléculas oxigênio reativas, denominadas de ERMO, é produzida em uma condição basal através do metabolismo aeróbico normal dentro das células renais, porém, quando em evolução a IRC, ocorre uma hipertrofia e hipertensão glomerular dos néfrons remanescentes, na tentativa de manter a TFG, durante este processo, no tecido renal ocorre um acréscimo da fosforilação oxidativa celular, isto promove um aumento de espécies reativas do metabolismo do oxigênio, que são potencialmente lesivas. Ainda, estes pacientes possuem uma deficiência relativa de sistemas de defesa antioxidantes, que atuariam sobre estas substâncias (Scott, 2008). A ativação crônica de substâncias oxidativas passa a ser patológica, tal qual na uremia, contribuindo para dano celular e tecidual sistêmico (Locatelli et al., 2003).

As ERMO de ação importante nos rins incluem o superóxido, peróxido de hidrogênio, radical hidroxila, ácido hipocloroso, lipídios, peróxido nitrito, ácido peróxido nitroso e hidroperóxidos entre outros, estas substâncias são altamente reativas, e presentes em excesso danificam lipídios, proteínas, DNA e carboidratos, conduzindo anormalidades funcionais e estruturais levando a apoptose celular e necrose. Geradores potenciais destas espécies reativas do metabolismo do oxigênio no tecido renal compreendem as células glomerulares, células tubulares e macrófagos (Galle, 2001; Scott, 2008).

A cadeia respiratória mitocondrial representa a fonte mais importante de oxidantes nos rins como parte da fosforilação oxidativa. A primeira substância reativa com o oxigênio, formada pelo organismo, é o superóxido. O sistema de enzimas NADPH-oxidase (nicotinamida adenina dinucleotídeo fosfato - forma reduzida), encontrado nas membranas das células reduz o oxigênio molecular em ânion superóxido, altamente instável, que logo a seguir é convertido a peróxido de hidrogênio pela enzima superóxidodismutase. O peróxido de hidrogênio é, por sua vez, reduzido em água e oxigênio moleculares ou pela catalase ou glutationa 
peroxidase, a qual utiliza a glutationa como doador de hidrogênio. Entretanto, na presença de metais de transição (ferro ou cobre) ou excesso de superóxido, o peróxido de hidrogênio, é convertido ao radical hidroxila, sabiamente o radical mais citotóxico existente. Na presença do cloro, a mieloperoxidase oriunda dos neutrófilos, converte o peróxido de hidrogênio em ácido hipocloroso. Este é um composto poderoso capaz de oxidar muitas moléculas como lipídeos e outros constituintes intracelulares, particularmente proteínas de membrana do grupo dos tióis. O processo é conhecido como estresse clorinativo (Ferreira e Matsubara, 1997; Locatelli et al., 2003; Scott, 2008).

O óxido nítrico é um radical livre com potente efeito vasodilatador potente, conhecido também como fator relaxante derivado do endotélio vascular, é um gás lipofílico bastante instável, que possui vida média em tecidos biológicos de aproximadamente 1 a 5 segundos (Locatelli et al, 2003). Sua síntese é iniciada a partir do substrato L-arginina, pela ação enzimática do óxido nítrico sintase. O óxido nítrico reage rapidamente com o oxigênio tanto na fase gasosa como em solução aquosa, formando o gás dióxido de nitrogênio. A forma induzível da enzima óxido nítrico sintase é ativada via elevação de cálcio intracelular, pela estimulação da acetilcolina e bradicina (Locatelli et al., 2003). Essa forma induzível da enzima óxido nítrico sintase é também sintetizada quando na ocorrência de um estímulo específico, em geral, um processo inflamatório. As ERMO inativam o óxido nítrico, pelos superóxidos, promovendo sua deficiência funcional e formação de produtos citotóxicos, como peróxido nitrito e ácido peróxido nitroso. $\mathrm{O}$ peróxido nitrito é um gatilho para a peroxidação lipídica, podendo causar danos ao DNA e nitração de proteínas (Locatelli et al. 2003).

O ânion superóxido e a hidroxila são os que realmente possuem estrutura de radical livre, sendo as demais consideradas espécies intermediárias que, através de diferentes reações, originam os radicais livres. Apesar de serem produtos menos reativos, podem produzir lesão celular através da peroxidação dos lipídeos das membranas mitocôndrias, dos lisossomos e membrana plasmática, alterando não só sua estrutura como também sua fisiologia (Shimizu, 2005).

Animais com IRC têm frequentemente condições simultâneas que aumentam a geração de espécies reativas do metabolismo do oxigênio, como a idade avançada, a ativação do sistema reninaangiotensina-aldosterona e desordens sistêmicas diversas. A presença de fibrose intersticial no tecido renal promove uma deficiência na atividade mitocondrial local, promovendo assim a geração das espécies reativas do metabolismo do oxigênio. A presença da anemia nestes pacientes exacerba este problema, pois a hipóxia aumenta a geração de espécies reativas do metabolismo do oxigênio, e o eritrócito possui uma ação antioxidante renal (Scott, 2008). O componente lipídico da membrana eritrocitária está também sujeito à agressão oxidativa. Os produtos desta lipoperoxidação podem induzir o estresse oxidativo intracelular, e se a defesa antioxidante estiver deficiente ocorrerá à hemólise (Ferreira e Matsubara, 1997).

O aumento do estresse oxidativo e inflamação ocorrem no paciente renal crônico, e têm sido associados à disfunção endotelial, contribuindo para o risco de doenças cardiovasculares, principalmente a hipertensão arterial sistêmica (Locatelli et al., 2003; Zafarullah et al., 2003).

A hipertensão arterial sistêmica contribui significativamente com a morbidade cardiovascular e mortalidade dos pacientes renais crônicos. Esta relacionada diretamente com o sistema renina-angiotensina-aldosterona e também com a peroxidação lipídica. As substâncias reativas geram nos vasos, inflamação, 
adesão de moléculas, depósito de proteínas na matriz extracelular, entre outros (Shimizu, 2005). A disfunção endotelial vascular é caracterizada por alterações no relaxamento vascular, por deficiência de óxido nítrico, que promove uma vasoconstrição e aumento da expressão da superfície vascular e aderência de moléculas tais como VCAM1, ICAM-1 e E-selectin, servindo como receptores de leucócitos circulantes nas artérias, que são atraídos por meio da transcrição nuclear Kaapa B (NF- $\kappa \beta)$, TNF- $\alpha$ e IL-1, estabelecendo assim 0 processo inflamatório (Scott, 2008).

A angiotensina II, em particular, é um fator importante para o estresse oxidativo renal, pois aumenta a produção de espécies reativas do metabolismo do oxigênio, nas células glomerulares e células tubulares, promovendo também uma vasoconstrição da arteríola eferente, que reduz o fluxo sanguíneo, aumentando a filtração glomerular, pelo aumento da pressão capilar, contribuindo para 0 estresse oxidativo no néfron. Além disso, a arteríola eferente quando constrita limita o fluxo sanguíneo a vasos capilares peritubulares, produzindo uma hipóxia tecidual e geração de mais espécies reativas do metabolismo do oxigênio (Scott, 2008).

A aldosterona também tem sido implicada como atuante no estresse oxidativo renal, através da participação no processo inflamatório, fibrose tecidual e esclerose nos rins (Nistala et al., 2008). Em um estudo realizado por Shibata et al (2007), demonstraram que a aldosterona administrada em infusão contínua associada a uma dieta rica em sódio em ratos, promoveu hipertensão e glomeruloesclerose.

Outro fator de risco importante para o estresse oxidativo renal é a proteinúria. A ativação crônica do sistema reninaangiotensina-aldosterona também provoca proteinúria. A hipertensão capilar glomerular leva a um aumento da permeabilidade glomerular e excessiva filtração de proteínas. Este sistema também pode causar proteinúria através da expressão de nefrina. Esta é uma proteína transmembrana localizada nos "slits" diafragmáticos dos podócitos glomerulares. Pela manutenção da integridade destes "slits", a nefrina limita a perda de proteínas pelo glomérulo. Quando sua expressão é alterada ocorre a proteinúria. Proteínas presentes na urina são tóxicas para os túbulos e podem provocar inflamação tubulointersticial (Shimizu, 2005; Scott, 2008).

Os compostos oxidantes são altamente reativos, com meia vida de alguns segundos. Portanto, sua determinação in vivo não é confiável. Em contraste, lipídeos, proteínas, carboidratos e ácidos nucléicos, após serem modificados pelos oxi-radicais, têm sua vida em torno de horas ou semanas, o que os torna marcadores ideais de estresse oxidativo. Estão inclusos nesta categoria o malondialdeido e o F2-isoprostano, entre muitas outras denominadas substâncias reativas (Locatelli et al, 2003).

O malondialdeído é um aldeído de cadeia curta. Sua formação ocorre pela decomposição dos hidroperóxidos lipídicos e sua concentração tem sido utilizada para estimar a intensidade da peroxidação lipídica em sistemas biológicos, em células e tecidos (Mafra et al., 1999).

O F2-isoprostano é produto da oxidação do ácido araquidônico, servindo como substrato estável de marcadores de radicais livres, que atacam as membranas das células in vivo (Locatelli et al., 2003).

\section{Antioxidantes}

Frente à ação potencial lesiva destas substâncias reativas, que são as ERMO, torna-se vital um controle delicado de sua produção e consumo dentro das células, o que é possível graças à ação dos antioxidantes que, removendo as substâncias reativas, as mantêm em concentrações baixas (Shimizu, 2005). 
Os antioxidantes podem ser enzimáticos (glutationa, superóxido dismutase, catalase), ou não enzimáticos, como os flavonóides e as vitaminas $\mathrm{C}$ e $\mathrm{E}$. O primeiro antioxidante endógeno que atua na defesa celular é o tiol (componente sulfidril), tal como a glutationa, sendo que a glutationa é o mais importante antioxidante endógeno, que na forma reduzida, glutationa peroxidase, age com os radicais, formando glutationa oxidada e água. A glutationa peroxidase atua tanto sobre os peróxidos lipídeos como sobre a água oxigenada, reduzindo-os na presença de glutationa (fornecedora de hidrogênio). A degradação de peróxido de hidrogênio é um passo importantíssimo, pois é a partir desta espécie que se origina o radical hidroxila, iniciador da peroxidação lipídica. No estresse oxidativo ocorre redução da atividade do sistema da glutationa. A atividade da glutationa peroxidase é criticamente dependente de selênio, em cuja presença ocorre a transcrição regular do RNA mensageiro para formação da glutationa peroxidase. Dietas deficientes em selênio prejudicam a expressão do RNA mensageiro para formação daquela enzima (Nath e Salahudeen, 1990; Knudsen et al., 1996; Locatelli et al., 2003; Zafarullah et al., 2003; Luciak, 2004). Adicionalmente, a deficiência de selênio promove aumento da degradação de vitamina E (Nath e Salahudeen, 1990; Knudsen et al., 1996; Locatelli et al., 2003; Zafarullah et al., 2003; Luciak, 2004).

Existem duas vias de aparecimento de mais radicais livres. Uma delas é o caminho dos hidroperóxidos, resultando em produtos menores e mais estáveis, os aldeídos. O outro caminho é a via dos endoperóxidos, resultando em malondialdeído e álcoois. O fenômeno da peroxidação de um ácido graxo poliinsaturado dá-se justamente devido à existência de várias insaturações em sua molécula; é na ligação dupla que o radical peróxido se insere, formando, então, um lipoperóxido. A vitamina $\mathrm{E}$ atua neste passo, reduzindo novamente os carbonos da ligação dupla. A presença desta vitamina bloqueia a transferência de elétrons de uma molécula para outra, amenizando uma série de danos e impedindo o início da propagação da peroxidação dos lipídeos. Esta pode ser iniciada pelo hidrogênio e peróxidos orgânicos, metabólitos celulares que são inativados pela glutationa peroxidase. Desse modo, a vitamina $E$ atua como um protetor de membrana celular (Locatelli et al., 2003; Shimizu, 2005).

Estudos realizados por Nath e Salahudeen (1990), descrevem que ratos que foram submetidos a ablação renal, com restrição de vitamina $E$ e selênio na dieta, apresentaram proteinúria mais intensa e aumento da pressão arterial.

Experimentos realizados por Suliman et al (2002) avaliaram as concentrações plasmáticas de glutationa em pacientes humanos renais crônicos em graus diferentes de anemia, sendo constatado que, quanto menor o hematócrito, maior a diminuição das concentrações de glutationa total no interior das hemácias, indicando a diminuição dos mecanismos antioxidantes de defesa em pacientes renais.

Bildik et al. (2004) determinaram as concentrações eritrocitárias de glutationa reduzida e as concentrações plasmáticas de marcadores de peroxidação lipídica, vitamina $C$, beta-caroteno, retinol e ceruloplasmina em cães com Leishmaniose visceral. Nesse estudo, as concentrações plasmáticas de marcadores de peroxidação lipídica foram maiores nos animais infectados pelo parasita do que nos animais normais, sugerindo aumento da peroxidação lipídica no plasma dos animais infectados.

Barros et al (1999) avaliaram as concentrações plasmáticas de marcadores de peroxidação e vitamina $\mathrm{C}$, e as concentrações eritrocitárias das enzimas glutiona-peroxidase, catalase, superóxidodismutase e glicose-6-fosfato desidrogena- 
se em cães da raça cocker spaniel inglês, com catarata. Detectou-se aumento nas concentrações plasmáticas de marcadores de peroxidação lipídica e diminuição das concentrações plasmáticas de vitamina $C$, indicando diminuição das defesas antioxidantes e aumento da peroxidação lipídica nesses animais.

Elias et al (2004) analisaram a fragilidade osmóstica dos eritrócitos em concentrações decrescentes de solução salina, em gatos hígidos, gatos com enfermidades hepáticas e com insuficiência renal. Neste estudo foram avaliados 27 animais, sendo que a hemólise de $50 \%$ foi notada de forma similar em todos os grupos. Em 100\% de hemólise, os eritrócitos de gatos com insuficiência renal apresentaram maior fragilidade osmóstica seguidos dos gatos com doença hepática. Acredita-se que a fragilidade osmótica dos eritrócitos felinos, à semelhança de que ocorre em outras espécies, possa ser influenciada por alterações metabólicas decorrentes de processos mórbidos, dentre elas o estresse oxidativo.

Lustoza (2004) avaliou as concentrações plasmáticas de glutationa total, reduzida e oxidada, superóxido-dismutase e o marcador de peroxidação lipídica malondialdeído em cães sadios e com IRC e constatou ausência de diferença significante nas concentrações eritrocitárias da glutationa total e glutationa reduzida entre os grupos. Porém, houve aumento considerável nos valores das concentrações eritrocitárias de glutationa oxidada e da atividade enzimática eritrocitária superóxido-dismutase em cães com IRC. Nestes animais, ainda, foram observadas concentrações plasmáticas maiores do marcador de peroxidação lipídica; desse modo, os resultados obtidos sugerem aumento do estresse oxidativo renal nos cães com IRC.

Buranakarl et al. (2008) avaliaram parâmetros para o estresse oxidativo renal e características dos eritrócitos em 15 cães saudáveis e 33 cães azotêmicos, neste estudo foi observado que os cães com insuficiência renal crônica apresentaram uma redução o volume corpuscular médio, e aumento da concentração da hemoglobina, como também a elevação dos marcadores do estresse oxidativo, principalmente o malondialdeído urinário.

\section{CONSIDERAÇÕES FINAIS}

A literatura consultada constata a existência do estresse oxidativo na espécie canina e principalmente do estresse oxidativo renal.

Novas pesquisas são necessárias para que se encontre, através do uso de antioxidantes, alternativas terapêuticas na atenuação da progressão da doença renal crônica, prolongando e melhorando a qualidade de vidas destes pacientes

\section{REFERÊNCIAS}

BARROS, P. S.M.; ANGELOTTI, A.C.; NOBRE, F. et al. Antioxidant profile of cataractous english cocker spaniels. Veterinary Ophthalmology, v.2, n.2, p.83-86, 1999.

BERNABEU, A.S.; TRIANA, B.E.T.; CASANOVA, A.E. et al. El Estrés Oxidativo en La Insuficiencia Renal Crônica. Revista Cubana Invest Biomed, v.23, n.2, p.118-120, 2004.

BILDIK, A.; KARGIN, F.; SEYREK, K. et al. Oxidative stress and non-enzymatic antioxidat status in dogs with visceral leishmaniasis.

Research in Veterinary Science, v.77, n.1, p.6366, 2004.

BROWN, S.A.; CROWELL, W.A.; BROWN, J.A. et al. Pathophysiology and Management of Progressive Renal Disease. The Veterinary Journal, v.154, n.2, p.93-109, 1997.

BURANAKARL, C.; TRISIRIROJ, M.; PONDEENANA, T. et al. Relationships between oxidative stress markers and red blood cell characteristics in renal azotemic dogs. Research in Veterinary Science, v.10,n.2, p.1010-103, 2008.

ELIAS, F.; LUCAS, S.R.R.; HAGIWARA, M.M. et al. Fragilidade osmótica eritrocitária em gatos acometidos por hepatopatias e gatos com insuficiência renal crônica. Ciência Rural, v.34, n.2, p.413-418, 2004.

FELDMAN, E.C. Disorders of the parathyroid glands. In: ETTINGER, S.J.; FELDMAN, E.C. 
Textbook of veterinary internal medicine. 4 ed. Philadelphia: WB. Saunders, 1995. p.1437-1461.

FERREIRA, A.L.A.; MATSUBARA, L.S. Radicais livres: conceitos, doenças relacionadas, sistema de defesa e estresse oxidativo. Revista da

Associação Médica Brasileira, v.43, n.1, p.61-68, 1997.

GALLE, J. Oxidative stress in chronic renal failure. Nephrology Dialysis Transplantation, v.16, n.11, p.233-235, 2001.

INTERNATIONAL RENAL INTEREST SOCIETY. Staging Chronic Kidney Disease (CKD).

Disponível em: <http://www.iris-

kidney.com/pdf/IRIS\%20A4\%20 Poster.pdf >. Acesso em 10/08/2009.

KING, L.G.; GIGER, U.; DISERENS, D. et al. Anemia of chornic Renal Failure in dogs. Journal of Veterinary Internal Medicine, v.6, n.5, p.26470, 1992.

KNUDSEN, C.A.; TAPPEL, A.L.L.; NORTH, J.A. Multiple antioxidants protect against heme protein and lipid oxidation in kidney tissue. Free Radical Biology \& Medicine, v.20, n.2, p.165-173, 1996.

LAURINDO, F.R.M. Desequilíbrio Redox. Resposta Cardiovascular à lesão da aterosclerose. Endotélio e Doenças Cardiovasculares. In: Da Luz L.P.; Laurindo, C.P.A. (Ed.). São Paulo: Atheneu. 2003. p.97-113.

LOCATELLI, F.; CANAUD, B.; ECKARDT, K.U. et al. Oxidative stress in end-stage renal disease: an emerging threat to pacient outcome. Nephrology Dialysis Transplantion, v.18, n.7, p.1272-1280, 2003.

LUCIAK, M. Antioxidants in the treatment of patients with renal failure. Annales Academiae Medicae Bialostocensis, Roczniki Akademii Medycznej Białymstoku. Disponível em: <http://www.sanum-per-aquam.de/pdfs/spa-studyalkaline-04.pdf> . Acesso em: 01/08/09.

LUSTOZA, M.D. Avaliação do estresse oxidativo em cães com insuficiência renal crônica e anemia 2004. São Paulo, 91f. Dissertação (Mestrado em Medicina Veterinária) Curso de PósGraduação em Medicina Veterinária, Universidade de São Paulo.

MAFRA, D.; ABDALLA, D.S.P.; COZZOLINO, S.M.F. Peroxidação lipídica em pacientes com insuficiência renal crônica. Revista de Nutrição, v.12, n.3, p.205-212, 1999.

MAHONEY, C.A.; ARIEFF, A.I. Central and Peripheral nervous system effects of chronic renal failure. Kidney International, v.24, n.2, p.170-177, 1983.
McGRATH, L.T.; DOUGLAS, A.F.; McCLEAN, E. et al. Oxidative stress and erythrocyte membrane fluidity in patients undergoing regular dialisys. Clinica Chimica Acta, v.235,n.2, p.179-188, 1995.

NAGODE, L.A. Renal secondary hyperparathyroidism. In: ANNUAL MEETING OF SOCIETY FOR COMPARATIVE ENDOCRINOLOGY, 4., 1990. Washington. Proceedings... Society for Comparative Endocrinology, 1990. p.17-26.

NATH, K.A.; SALAHUDEEN, A.K. Induction of renal growth and injury in the intact rat kidney by dietary deficiency of antioxidants. The Journal of Clinical Investigation, v.86, n. 4, p.1179-1192, 1990.

NICHOLS, R. Polyuria and Polydipsia. Veterinary Clinics North America: Small Animal Practice, v.31, n.5, p.833, 2001.

NISTALA, R.; CONNELL, W.A.; SOWERS, R.J. Antioxidant \& Redox Signal. National Institutes of Healt, v.12, n.12, p.2047-2089, 2008.

PANZETTA, O.; COMINACINI, L.; GARBIN, U. et al. Increased susceptibility of LDL to in vitro oxidation in patients on maintenance hemodialysis: effects of fish oil and vitamin $E$ administration. Clinical Nephrology, v.44, n.5, p.303-309, 1995.

POLZIN, D.J.; OSBORNE, C.A. Dietary Management of Canine Renal Failure. In: BREITSCHWERDT, E. B. Nephrology and urology, 1.ed. New York: Churchill Livingstone, 1986. p.151-176.

POLZIN, D.J.; OSBORNE, C.A.; BARTGES, J.W. Chronic renal failure. In: ETTINGER, S.J.; FELDMAN, E.C. Textbook of veterinary internal medicine. 5.ed. Philadelphia: W. B. Saunders, 2000. p.1634-1662.

POLZIN, D.J.; OSBORNE, C.A.; ROSS, S. Chronic renal failure. In: ETTINGER, S.J.; FELDMAN, E.C. Textbook of veterinary internal medicine. 6 ed., Philadelphia: W.B.Saunders, 2005. p.1756-1785.

ROSS, L. Hypertension and chronic renal failure. Seminars in Veterinary Medicine and Surgery (small animal), v.7, n.3, p.221-226, 1992.

SCOTT, A.N.D. Oxidative stress and chronic kidney disease. Veterinary Clinical Small Animal, v.38, n.1, p.157-166, 2008.

SENIOR, D.F. Management of chronic renal failure in the dog. The compendium colletion, Treaton, NJ: Veterinary Learning System, 1994.

SHIBATA, S.; NAGASE, M.; BLECHA, F. et al. Podocyte as the target for aldosterone: roles of oxidative stress and SgKL. Hypertension, v.49, n.2, p.355-364, 2007. 
SHIMIZU, M.H.M.A. N-acetilcisteína atenua a progressão da doença renal crônica. 2005. Ribeirão Preto, 105f. Tese (Doutorado em Medicina) Universidade de São Paulo USP.

SULIMAN, M.E.; BÁRÁNY, P.; DIVINO FILHO, J.C. et al. Influence of nutritional status on plasma and erythrocyte sulphur amino acids, sulph-hydryls, and inorganic sulphate in end-stage renal disease.

Nephrology Dialysis Transplantation, v.17, n.6, p.1050-1056, 2002.
ZAFARULLAH, M.; LI, W.Q; SYLVESTER J. et al. Molecular mechanisms of $\mathrm{N}$-acetylcysteine actions. Cellular and Molecular Life Sciences, v.60, n.1, p.6-20, 2003. 